\title{
Percepções dos impactos de festivais culturais numa comunidade: o caso do Festivelhas Jequitibá/MG (Brasil)
}

\author{
Perceptions of the impacts of cultural festivals in a community: the case of \\ Festivelhas Jequitibá/MG (Brazil)
}

Fábio Costa Pedro (PEDRO, F. C.) *

\begin{abstract}
RESUMO - Os festivais de cultura podem contribuir para a valorização do patrimônio cultural de uma localidade que aliada à atividade turística podem promover a autoestima e a melhoria das condições de vida da população. Buscou-se investigar neste artigo a relação entre o Festivelhas, evento do Projeto Manuelzão da Universidade Federal de Minas Gerais (UFMG) em Jequitibá (MG/Brasil) e os impactos socioculturais desse festival na cidade conhecida como "a capital mineira do folclore", localizada às margens do rio das Velhas. Foi elaborado a partir dos dados obtidos de observação direta do evento ocorrido em 2007 e 2008. O Festivelhas ao envolver cultura, turismo e a comunidade constitui-se em recurso turístico contribuindo para o desenvolvimento local. Como resultado conclui-se que o Festivelhas a partir de ações nas quais existiu o equilíbrio entre os interesses da comunidade e os do mercado trouxe turista, gerou renda e propiciou uma grande oportunidade da cidade valorizar sua herança cultural imaterial.
\end{abstract}

Palavras-chave: Festivelhas Jequitibá/MG; Festivais; Cultura; Patrimônio cultural; Turismo cultural

ABSTRACT: The culture festivals may contribute to the cultural source of a given place. This activity associated to the tourism may enhance the self-esteem and improve the life condition of local population. In this work, we investigated the relationship between the Festivelhas, an event from Manuelzão project, UFMG (Universidade Federal de Minas Gerais), that took place in Jequitibá/MG and the socio-cultural impact caused in this city, known by the name: "The folklore capital of Minas", localized by Velhas River (Rio das Velhas). When Festivelhas involves culture and community, it becomes a touristic resourse and contributes to local development. In conclusion we can state that since Festivelhas equalized the interests from the local community and from the market, it brought tourists, profits, and allowed a big opportunity to the city to valve its immaterial cultural heritage.

Key words: Festivelhas Jequitibá/MG; Festivals; Culture; Cultural heritage; Cultural tourism

\footnotetext{
* Graduado em História (UFMG) e Mestre em Turismo e Meio Ambiente pelo Centro Universitário UNA, Belo Horizonte, MG. Professor de História do Centro Pedagógico da UFMG. Endereço: Avenida Antônio Carlos 6627 (Campus Pampulha). CEP: 31270-901 - Belo Horizonte - MG (Brasil). Telefone (31) 34212972. Email: dir@cp.ufmg.br
} 


\section{INTRODUÇÃO}

Este artigo aborda os impactos socioculturais do Festivelhas que ocorreu em setembro de 2007 na cidade de Jequitibá/MG, conhecida como a capital mineira do folclore. O evento de iniciativa do Projeto Manuelzão, faz parte de um programa de extensão da Universidade Federal de Minas Gerais que tem por objetivo promover a revitalização da bacia do rio das Velhas. Em Jequitibá reuniram-se entre os dias 6 a 9 de setembro representantes dos comitês dos 51 municípios da bacia do rio das Velhas. A proposta do Festivelhas Jequitibá é a de ser um espaço para discussão entre agentes culturais, mobilizados pela melhoria das condições ambientais da bacia do rio das Velhas. O Festivelhas Jequitibá busca revelar também o patrimônio cultural da bacia do rio das Velhas e sua relação com a agenda ambiental por meio de debates, palestras, oficinas, exibição de vídeos, apresentações musicais, teatrais e folclóricas.

Também se buscou apresentar considerações referentes ao ano 2008 visando atualizar os dados e ao mesmo tempo identificar se houve evolução ou acréscimos em relação a 2007.

O texto está estruturado em quatro partes: na primeira parte do artigo é feita uma contextualização histórica da cidade e seu patrimônio imaterial; e em seguida é feita uma reflexão sobre o valor do patrimônio imaterial para uma localidade; na terceira parte é feita uma descrição da metodologia empregada e finalmente na quarta parte são enunciados os resultados da pesquisa e a conclusão.

\section{JEQUITIBÁ E O PATRIMÔNIO IMATERIAL}

A cidade de Jequitibá localiza-se às margens do rio das Velhas, importante rota fluvial de penetração no território mineiro no período colonial. A região foi explorada pela expedição de Fernão Dias, que adentrou no sertão das Minas Gerais a procura de ouro e pedras preciosas subindo o rio das Velhas até Sabará. Essa região foi também percorrida pelo bandeirante Borba Gato, do qual se assegura ter sido o primeiro povoador e minerador do rio das Velhas na região da atual Sabará/MG. A cidade 
chegou a contar com um porto fluvial porque durante a fase imperial (1822-1889) foram várias as tentativas de navegar pelo rio das Velhas, inclusive de navegação a vapor.

A cidade de Jequitibá faz divisa com os municípios de Santana de Pirapama, Cordisburgo, Araçaí, Funilândia, Baldim e Sete Lagoas. Pela diversidade e grande número de manifestações populares ligadas ao catolicismo a cidade graças a iniciativas de alguns apreciadores da cultura popular tornou-se conhecida como a capital mineira do folclore. Essa herança cultural ligada ao catolicismo assume importante fator de identidade nessa comunidade mineira às margens do rio das Velhas. A cidade de Jequitibá que foi cogitada a ser a capital política do Estado de Minas Gerais ficou esquecida à beira do rio das Velhas, acabou assumindo a identidade de "capital mineira do folclore", mensagem propagada oficialmente pelo poder público local.

Em Jequitibá, as celebrações tradicionais envolvem os cantos, as músicas, a dança, as crenças, os ritos, a culinária e o artesanato constituindo-se numa herança transmitida por gerações formando um singelo patrimônio imaterial que evoca o sagrado com atos comemorativos e rituais ligados ao trabalho como a dança do Serrador e a dança do Tear. Os produtores dessa herança são trabalhadores rurais que como congadeiros, foliões, batuqueiros, encomendadores de alma, dispersos por seu território configuram a identidade local de celebrações ligadas ao catolicismo.

Entre as celebrações que ocorrem na sede do município de Jequitibá destacam-se as folias do mestre Nelson Jacó que são grupos precatórios de inspiração religiosa católica, integrados por cantores e instrumentistas que homenageiam os santos através de orações cantadas saindo às ruas e visitando as casas para pagamento de promessa. Outro destaque é a Guarda do Santíssimo Sacramento, de "Zé da Ernestina", responsável pelas apresentações Congo de Nossa Senhora do Rosário e pelas Folias de Reis, do Divino, de São Sebastião, de São Geraldo, de Nossa Senhora Aparecida; Batuque; e das danças Recortado; Dança de Fagote e Dança de Lundum. O ritual da folia e guarda começa com o cortejo pelas ruas da cidade, cantando, dançando e tocando as violas, as caixas, o chique-chique, cavaquinhos e rabeca. A guarda sai com o seu mestre à frente de uniforme branco e espada símbolos de sua dignidade e sabedoria. $\mathrm{O}$ cortejo visita à casa do festeiro onde os componentes almoçam e prosseguem pelas ruas terminando a festa com o levantamento do mastro da bandeira no adro da igreja em homenagem ao santo celebrado. 
No município de Jequitibá, outras manifestações populares ligadas ao catolicismo tradicional popular revelam-se nos seus diversos distritos. Além das folias e guardas ocorre a "Incelência para Chuva", cortejo onde os cantadores saem pelo povoado rezando o terço e cantando pedindo o fim da estiagem; a "Encomendação das Almas", ritual realizado durante a quaresma, quando os participantes saem durante a noite tocando matraca e pedindo que todos rezem pelas almas, principalmente daqueles que morreram em mortes trágicas; o "Batuque", dança de origem africana caracterizada por forte sapateado e palmas e que é acompanhado por tambores, caixas, pandeiros, violas e rabecas que dão base rítmica a cantigas tradicionais; a "Dança do Tear", que retrata a cultura do algodão do momento de se colher até o de se tecer. Nessa dança a coreografia imita os movimentos dos fios durante a tecelagem; a "Contra-Dança", feita sem canto nem letra, apenas ao som de violas rabecas e flautas. $\mathrm{Na}$ evolução da dança são usados lenços e porretinhos que são batidos uns nos outros; o "Fim de Capina", dança que representa o término da capina na roça, geralmente realizada em novembro e dezembro; a "Dança do Serrador", cantos que embalavam no passado os trabalhadores na dura tarefa de serrar troncos com serras manuais que exigiam muito esforço.

A revelação dessa identidade ligada às celebrações do catolicismo surgiu no final dos anos de 1988, graças ao trabalho dos admiradores dessas manifestações populares que identificaram esse patrimônio cultural popular como identidade e riqueza do município. A idéia não teve repercussão imediata junto ao poder público local e mesmo junto à comunidade que considerava a idéia como um desatino de alguns apreciadores das folias, guardas e congado.

Apesar da incompreensão a idéia desses visionários concretizou-se com o lançamento em julho de 1991 de um movimento cultural de setores dessa comunidade chamado de "governo do folclore" onde simbolicamente foram empossados na ocasião o "Governador do Estado Mineiro do Folclore", Frei Chico e "Vice-Governador", o cantor Saulo Laranjeira e auxiliares: "Prefeito da Capital Mineira do Folclore", Geraldo Antônio Saturnino; Chefe da Imprensa, Carlos Felipe Marques Horta; Secretário Plenipotenciário de Segurança Pública e Preservação do Folclore, Geraldo lnocêncio de Souza; Reitora da Universidade Folclórica de Santo Antônio do Baú, a Professora Núbia Pereira de Magalhães Gomes e Vice-Reitor, Professor Edmilson de Almeida Pereira; Reitor da Universidade Folclórica de Jequitibá, o poeta Oswaldo Saturnino 
Lopes e Vice-Reitor, Adib Reis. Esse movimento deu a Jequitibá o título simbólico de "capital mineira do folclore". Esse governo do folclore teve vida efêmera, mas foi um marco na tentativa de resgate das tradições culturais da cidade.

Em 1993, foi criada a Festa do Folclore que se realiza nas ruas centrais da cidade e que reúne na sede do município no mês de setembro os grupos de folias, congado e danças do município onde ocorrem as danças, os cantos a culinária e o artesanato reunindo todos os grupos performáticos do município.

Esse patrimônio cultural da cidade ligado à tradição católica ensejou que a mesma fosse escolhida para receber o Festivelhas em disputa com outras duas cidades mineiras que integram a bacia do rio das Velhas, Santa Luzia e Sabará. O patrimônio cultural deu a Jequitibá visibilidade e a oportunidade de divulgar sua herança pela bacia do rio das Velhas e pelo Estado uma vez que reuniu artistas, agentes culturais, ambientais e teve cobertura das redes de televisão da capital. Para o Projeto Manuelzão ${ }^{1}$ era preciso olhar as festas como as danças, o Congado e instrumentos como a viola, como fazendo parte do cotidiano da comunidade. Deste modo, a valorização desse patrimônio cultural pode favorecer a identificação da população com sua terra e seus problemas.

\section{OS IMPACTOS SÓCIO-CULTURAIS DO FESTIVELHAS JEQUITIBÁ}

O Festivelhas Jequitibá mobiliza os gestores públicos da localidade que preparam a infra-estrutura para receber os turistas, os artistas e organizadores do evento. A sede do município que conta com uma população de 5.491 habitantes (IBGE, 2008), recebe as pessoas das equipes de apoio do Projeto Manuelzão que preparam a infraestrutura para os shows, a recepção dos artistas e representantes dos núcleos Manuelzão, subcomitês, moradores da bacia, pesquisadores e professores de escolas públicas da bacia do rio das Velhas. Constatou-se que os visitantes de 2007 tinham 70\% deles idade entre 30 e 60 anos conforme os dados obtidos em razão de um processo de inscrição

\footnotetext{
${ }^{1}$ Festivelhas Jequitibá. Disponível em:<http://www.manuelzao.ufmg/folder_atuacao/folder_festivelhas/in dex_hdml>. Acesso em: 04/09/ 2007.
} 
cheio de especificações, tais como: cadastros com a idade, sexo, e até a possibilidade de acampar ou de trazer colchões.

$\mathrm{Na}$ época, os gestores locais para atender um público estimado pelo projeto de 500 inscritos mais os excursionistas e turistas calculados em torno de mil pessoas, tiveram que cuidar de alojamentos entre hotéis, pousadas, área de camping, casas particulares para alugar; alimentos e bebidas divididos entre restaurantes, barraquinhas e comércio local. Para que a renda gerada pela presença dos excursionistas e turistas na cidade fosse distribuída da melhor maneira possível os gestores locais ${ }^{2}$ se reuniram com os artesãos, e comerciantes no planejamento e administração do evento.

Foram credenciados cinco locais capazes de fornecer alimentação e bebidas sendo que os atendentes foram instruídos com relação à higiene e à recepção aos turistas. Cada um dos 500 credenciados do Projeto Manuelzão inscritos no Festivelhas recebeu 12 cupons para os quatro dias o que lhes garantia 3 refeições diárias no valor de $\mathrm{R} \$ 4,00$ (quatro reais), preço estipulado para cada prato feito nos locais credenciados. $\mathrm{O}$ setor de hospedagem da cidade foi responsável pelo embolso de maior quantia, com 2 hotéis e uma pousada arrecadando aproximadamente $\mathrm{R} \$ 30.000,00$ (trinta mil reais) pelo aluguel de suas dependências aos credenciados do festival, ao pessoal do setor de apoio e infra-estrutura do projeto Manuelzão e artistas convidados.

Muitos visitantes da cidade ficaram em acampamentos com infra-estrutura montada especialmente para o festival o que gerou renda para o comércio no entorno desses locais. Em relação ainda à infra-estrutura a cidade providenciou junto aos proprietários o aluguel de casas e espaços públicos como as escolas para a hospedagem e organizaram-se os expositores de artesanato e comidas típicas. A cultura propiciou nesses quatro dias uma renda extra, importante para o município, servindo como fator para motivar a comunidade e o setor público a atrair novos eventos culturais para o município. O festival mobilizou a administração municipal que forneceu o apoio logístico e recursos financeiros para os grupos performáticos do município na confecção das suas vestimentas e adereços para que se apresentassem junto a artistas expoentes da música mineira, entre eles: Chico Lobo, Fernando Sodré, e Rubinho do Vale. O município trouxe suas manifestações, tais como: a dança do Tear, Incelência para a chuva, dança do Fim da Capina, dança do Serrador, dança da Vara, cantiga de roda,

\footnotetext{
${ }^{2}$ SANTOS, Nivaldo. Entrevista concedida ao autor, Jequitibá/MG, 21 set. 2007.
} 
batuque, quadrilha folclórica, as pastorinhas, guarda do Congo de Jequitibá, folia do Divino, folia de São Sebastião e folia de Reis. Um dos mestres de arte popular da cidade Nelson Jacó se apresentou com o violeiro Chico Lobo, ex-integrante do grupo Aruanda de Danças Folclóricas e o violeiro português Pedro Mestre especialista em música tradicional alentejana.

A programação seguiu com oficinas, debates, palestras e vídeos que mobilizaram os participantes e visitantes do Festivelhas. As oficinas foram realizadas em frente à Igreja do Santíssimo e tiveram a participação do público infanto-juvenil que participou da confecção de esculturas, colagens, e pinturas a partir de material reciclado e materiais originários da natureza.

Nesse artigo, baseado nas observações do presente autor e no acompanhamento dos cinco números do boletim Festivelhas "de mão em mão" ${ }^{3}$ produzido por jornalistas e estudantes de Comunicação da Universidade Federal de Minas Gerais, entre os dias 6 e 9 de setembro de 2007, pôde-se avaliar o impacto do Festivelhas na comunidade. Para Vieira Filho (2006) os impactos do turismo são geralmente econômicos, ambientais e sócio-culturais e se inter-relacionam. Os impactos são percebidos positiva ou negativamente, dependendo de como os atores sociais processam informações e agem ao longo do tempo.

A percepção da comunidade acerca do Festivelhas foi positiva pelo envolvimento do setor público e da iniciativa privada que foi chamada a participar do planejamento do evento juntamente com o pessoal do Projeto Manuelzão. Esse impacto positivo pôde ser percebido nos depoimentos dos moradores entrevistados pelos comunicadores da UFMG para a edição dos boletins de "mão em mão". No "Boletim número 1, de 6 de setembro de 2007, na matéria "Jequitibá: a mesma, porém outra", percebeu-se pela fala da população local que a cidade já não era mais a mesma e que o Festivelhas havia trazido expectativas enormes. "Estabelecimentos comerciais promoveram melhorias, hotéis aumentaram as vagas [...] muitas pessoas estão pintando os muros e enfeitando as calçadas das casas, com a proximidade do Festival". Nesse

\footnotetext{
${ }^{3}$ BOLETIM, de mão em mão, números 1 a 5 , de 06 a 09 de setembro de 2007, mimeografado, Jequitibá/MG, 2007. EXPEDIENTE: Redação e edição: Elton Antunes, Carolina Silveira, Carlos Jáurequi, Humberto Santos, Filipe Motta, Mariana Garcia, Matheus Jasper, Sâmia Bechelane, Taís Ahouagi, Vanessa Veiga e Victor Guimarães. Diagramação: Carolina Silveira e Humberto Santos. Tiragem: 500 exemplares.
} 
boletim Nivaldo Santos na época responsável pela ligação entre a cidade e o Projeto Manuelzão ao apontar os efeitos positivos do Festivelhas depõe que "acredita que o turismo, por exemplo, deve crescer". Para o então gestor da cultura do município Hermano Saturnino "quando o público de fora valoriza a cultura da cidade, o jequitibaense eleva sua auto-estima".

Assim, a partir de tais citações pode-se afirmar que o turismo e o patrimônio quando atuam de forma articulada possibilitam valorizar a cultura e a herança cultural de um lugar levando a população local a apreciar mais sua cultura. Esses depoimentos também demonstraram quanto pode ser benéfica a relação entre patrimônio e turismo para uma comunidade, pois o visitante traz o estímulo externo contribuindo não apenas com renda para a cidade, mas também reforçando a identidade cultural da mesma, aumentando a auto-estima da população local. Assim, para Vieira Filho "o turismo traz renda e trabalho e propicia o intercâmbio cultural, mais alegria e movimento na cidade e o aumento da auto-estima, tornando a cidade e seu povo (re)conhecidos" (VIEIRA FILHO, 2006, p. 13).

Assim, durante os dias do Festivelhas 2007 a cidade de Jequitibá foi movimentada pelos turistas, pelos artesãos expondo seus produtos, pelos debates, palestras e vivências em frente à Igreja do Santíssimo onde foram realizadas oficinas, apresentações itinerantes, malabares e pintura para o público infanto-juvenil. A cidade foi movimentada pelos 500 inscritos no festival e pelos estimados mil excursionistas que passaram pela localidade. Segundo DIAS (2006) é importante a identificação da comunidade com seu patrimônio que é estimulado por meio de políticas que promovam a construção e o fortalecimento da identidade com ações de promoção, como o caso aqui relatado do Festivelhas Jequitibá. Para Dias a "ativação do patrimônio para atração turística, de modo a gerar uma movimentação econômica que contribua para o desenvolvimento, é um viés pouco abordado no turismo". (DIAS, 2006, p. 47)

No boletim de encerramento do Festivelhas 2007: "Até a Volta [...]" as palavras de uma moradora com 70 anos de Jequitibá, resumiram a importância da cultura como fator de desenvolvimento e de auto-estima de uma comunidade. Ela disse que tudo tinha ocorrido muito bem, que os visitantes foram muito educados e que trataram muito bem a comunidade. "De nossa parte, fizemos o que pudemos para servir bem a todos. Os artistas foram todos ótimos. O espaço era pouco para uma apresentação com tanta 
manifestação" 4 . A partir disso, pode-se afirmar que o patrimônio e sua relação com o turismo cultural fornecem reforço simbólico a comunidade, renda e ocupação e uma fruição prazerosa para convidados e anfitriões.

Referente ao ano 2008 optou-se em buscar informações também no site do evento, sem o mesmo grau de profundidade, diferenciando-se da metodologia utilizada no ano 2007, com um caráter mais indireto baseado principalmente na programação realizada. Isso com a finalidade de estabelecer um elo temporal entre os dois eventos.

\section{O PATRIMÔNIO CULTURAL E O TURISMO}

O conceito de patrimônio cultural foi ampliado ao longo do século XX e de bens de "pedra e cal", monumentos, obras de arte, pertencentes às elites civis e religiosas passa a incluir saberes, música, festas, danças, crenças que representam a cultura dos grupos étnicos e populares configurando-se como patrimônio vivo com sua dimensão intangível, que não se concretizam em objetos duráveis (LONDRES, 2001). O reconhecimento do patrimônio imaterial foi um processo lento e gradual e no Brasil se efetivou com a Constituição Federal de 1988 e pelo Decreto Federal 3551/2000. Ele compreende atualmente os bens portadores de referência à identidade, à memória dos diferentes grupos formadores da sociedade brasileira, nos quais se incluem: as formas de expressão; os modos de criar, fazer e viver; as criações científicas, artísticas e tecnológicas; as obras, objetos, documentos, edificações e demais espaços destinados às manifestações artístico-culturais; os conjuntos urbanos e sítios de valor histórico, paisagístico, artístico, arqueológico, paleontológico, ecológico e científico.

$\mathrm{O}$ patrimônio cultural no decorrer do século $\mathrm{XX}$ tornou-se um conceito de grande amplitude cujos aspectos constitutivos são a diversidade, e sua natureza sóciopolítica ligada a processos de identidade de lugares e nações. O Patrimônio cultural é também atribuição de valor que pode ser o valor estético: beleza, e harmonia; o valor espiritual: crenças, fé; valor social: conexão com outros, um senso de identidade; o valor histórico: conexão com o passado; o valor simbólico: objetos como repositórios de

\footnotetext{
${ }^{4}$ FELIZARDO, Maria Francisca. Entrevista. Boletim do Festivelhas de mãos em mão, n. 5, de 09 de setembro de 2007.
} 
significados afetivos. Atualmente cresce em importância o valor de mercado: o patrimônio como recurso capaz de atender as aspirações espirituais e culturais dos turistas, de gerar renda e ocupação para a comunidade detentora da herança cultural. Cada vez mais o patrimônio representa para as localidades sua identidade cultural, autoestima e fonte de renda e geração de emprego (ARANTES, 2004).

O turismo apropriando-se do patrimônio cultural embora venha ganhando adeptos e apoios não é aceito sem controvérsias. Para os críticos do uso turístico do patrimônio não se pode descuidar dos efeitos negativos, nocivos e destrutivos que acarretam o uso descontrolado do patrimônio cultural. Para o antropólogo Carvalho (2004) as apropriações pelo mercado colocam em risco tradições que podem se desvincular de suas "dimensões locais de identidade, pertença, religiosidade, consciência histórica, criação estética, originalidade, fonte de auto-estima e resistência política", em decorrência de um suposto direito ao espetáculo da era do consumidor cidadão, que transforma rituais sagrados em entretenimento (CARVALHO, 2004, p. 79). Para esses críticos, o respeito ao patrimônio cultural, sua conservação, sua autenticidade merecem cuidados que devem prevalecer sobre qualquer outra consideração do ponto de vista econômico.

O valor de mercado do patrimônio que aparece nas Normas de Quito (1967) da Organização dos Estados Americanos - OEA (In: CURY, 2004) onde se estabeleceu que o valor econômico é um valor de troca atual capaz de evitar riscos de desaparecimento provocados pelo abandono e falta de proteção, surgindo o turismo como atividade capaz de reverter essa situação. O turismo aparece nessas Normas, como uma ferramenta de preservação do patrimônio sem que isso leve a sua desnaturalização. As Normas de Quito (1967) foram atualizadas pela Carta do Turismo Cultural (1976), do Conselho Internacional de Monumentos e Sítios (ICOMOS) ${ }^{5}$, onde o turismo é visto como fenômeno capaz de exercer um efeito positivo sobre o patrimônio porque contribui para a sua conservação de forma sustentável.

Na elaboração desse artigo buscou-se evidenciar o valor simbólico e de mercado do patrimônio imaterial de Jequitibá, e que sua apropriação pelo turismo é uma realidade que traz impactos positivos conforme constatado pela própria voz de seus moradores.

5 ICOMOS, Carta do turismo Cultural. In: SEMINÁRIO INTERNACIONAL DE TURISMO CONTEMPORÂNEO E HUMANISMO. Bruxelas, 1976. 
Para que os impactos positivos continuem a acontecer de maneira sustentável é necessário que além do turismo, existam intervenções do poder público e da comunidade na valorização dessa herança cultural representada pelos cantos, música, dança e interpretações. Como afirma Dias (2006) o patrimônio cultural é ainda um recurso pouco utilizado pelos municípios e no caso de Jequitibá sua apropriação pelo turismo pode proporcionar vantagens em relação a outros territórios, pois, o uso do patrimônio pelo mercado é uma tendência cada vez mais forte na sociedade atual.

\section{METODOLOGIA}

Esse trabalho é um estudo de caso baseado em bibliografia referente ao tema patrimônio cultural e turismo; em método de observação direta do autor e de análise nos meios de comunicação montados especialmente para o Festivelhas 2007 como o boletim “de mão em mão" e o site do Projeto Manuelzão. Conforme mencionado anteriormente, o boletim contou com uma tiragem de 500 exemplares por número que foram publicados num total de cinco, editados entre os dias 06 e 09 de setembro na cidade durante o evento e distribuídos entre os participantes do Festivelhas. Os estudantes de Comunicação, responsáveis pela elaboração do boletim entrevistaram os moradores e gestores do Festivelhas, e comentavam os acontecimentos de cada dia representando um olhar de fora sobre a cidade e seu patrimônio cultural e o Festivelhas. A redação do boletim e impressão coube aos jornalistas do projeto Manuelzão e equipe de estudantes de Comunicação da Universidade Federal de Minas Gerais. Utilizou-se também uma agenda impressa em um guia de bolso com todas as atividades do dia e da noite onde constavam as palestras, vivências e performances.

Buscou-se através do boletim "de mão em mão" uma fonte direta de referência para o artigo, pois seus redatores buscaram ouvir a voz dos moradores e gestores locais, através de entrevistas e depoimentos. Os dados coletados foram analisados, com apoio da bibliografia existente sobre o tema em estudo, ou seja, sobre a relação entre patrimônio e turismo.

Estipulou-se como objetivo geral do artigo analisar a relação entre o "Festivelhas Jequitibá" e seus impactos socioculturais e como fator de auto-estima (e renda) para 
uma comunidade cuja identidade encontra-se ligada ao seu patrimônio representado pela dança, música e canto vinculados ao catolicismo, patrimônio imaterial produzido pelas "mãos calejadas" de trabalhadores rurais.

Para a apresentação do presente artigo buscou-se confrontar o que foi observado em 2007 com o que ocorreu em 2008 objetivando atualizar informações e estabelecer um elo comparativo. As informações de 2008 foram obtidas através da pesquisa no site do festival e observação do autor entre os dias 05 e 07 de setembro de 2008 em Jequitibá.

\section{RESULTADOS E ANÁLISES}

O Festivelhas é uma grande oportunidade de visibilidade para as manifestações populares da cidade de Jequitibá que tem sua divulgação muito limitada à região em que se localiza apesar dos gestores públicos e a comunidade a proclamarem como a capital mineira do folclore. $\mathrm{O}$ evento aumentou a auto-estima dos moradores do município trazendo ocupação e renda para os artesãos instalados nas barraquinhas durante o festival, para os hotéis e pousadas e para os moradores responsáveis pela alimentação dos participantes credenciados. O Festival serve por tudo isso para motivar à conservação pela comunidade das tradições culturais da cidade mantidas ainda pela persistência dos mais velhos.

Durante o Festivelhas os gestores públicos se mobilizam para preparar não apenas a infra-estrutura da cidade, mas também fornecendo recursos para que os grupos do município se apresentem completos e com uma melhor qualidade dos suportes físicos como as vestes das apresentações. O Festivelhas ao atrair um público variado para a cidade revela e valoriza um dos componentes essenciais do seu patrimônio: a identidade da comunidade, processo esse onde o passado é uma referência propiciadora de identidade, mas que igualmente possibilita a construção do presente, tornando-se um recurso com valor de mercado e gerando benefício para seus detentores. A valorização do patrimônio a partir de atrativos como o Festivelhas se constitui em alternativa de renda e emprego para a comunidade, fator de auto-estima e fortalecimento da cultura local. 
Em relação aos possíveis impactos negativos como a espetacularização e dessacralização dessas manifestações, com base nas observações da festa e da leitura do boletim de mão em mão, observou-se em 2007 que os performáticos manifestaram visões diferentes com relação ao tema. Para "Zé da Ernestina", mestre de folias e guardas em Jequitibá, na Igreja é diferente da apresentação no palco: "no palco não é muito religioso". Para os cantadores da Encomendação das Almas, do distrito de Vera Cruz, "no palco ou no chão é a mesma coisa". A cultura é dinâmica (LARAIA, 2006) susceptível a mudanças por ser realizada pelos homens que não absorvem de forma neutra as transformações do mundo social. A discussão ocorre porque tanto o patrimônio imaterial como o material estão sujeitos a riscos trazidos pela mudança de hábitos e práticas tradicionais trazidas ou não pelo turismo. $\mathrm{O}$ posicionamento dos atores sociais de Jequitibá refletiu a dinâmica cultural, as mudanças trazidas pelo mercado independentemente do turismo.

No entanto como fenômeno cultural o patrimônio imaterial para Dias (2006) não pode ser congelado no tempo, como amostra viva do passado. Embora haja riscos do uso do patrimônio cultural para o turismo as vantagens são bem maiores que os prejuízos, "pois a atividade turística encontra novas funções para os bens culturais, de modo a torná-los um instrumento válido para o desenvolvimento sustentável” (DIAS, 2006, p. 50)

No final da apresentação do batuque do Festivelhas 2007 feita em playback, Fabiana Alves, filha de Zé da Ernestina na pose para as fotos apregoou: "Todo mundo diga 'Dinheiro'!". Esse é um grito simbólico que emite uma mensagem clara, o patrimônio para sobreviver tem que dar um retorno material para seus detentores, além de seu sentido simbólico e religioso. Quanto à espetacularização estipulando-se aqui a cultura como mercadoria pode-se concluir concordando com Dias (2006) que afirma que mesmo com adaptações ao turismo essas manifestações culturais continuam legítimas enquanto fontes de auto-estima e renda para a comunidade.

Considera-se que a experiência do Festivelhas conduziu a um novo formato da tradicional Festa do Folclore da cidade, a inclusão e participação de artistas convidados e a revitalização das manifestações tradicionais da cidade. Isso porque essas manifestações de dança, cantos e música se mantêm na cidade pela persistência dos mestres das folias e guardas que contornam as dificuldades de manutenção dos grupos 
como a falta de recursos financeiros e a pouca renovação dos performáticos. As adaptações podem revitalizar as manifestações tradicionais de Jequitibá ligadas às danças, aos cantos e à música das folias e guardas para que se constituam em atrativo para os festivais.

Essas adaptações e arranjos podem passar por algumas estratégias, conforme apresentadas em seguida: a primeira é a promoção da organização dos performáticos, o que significa incentivar a criação de uma associação encarregada de gerenciar essas manifestações; a segunda é a de educar as novas gerações através de oficinas realizadas nas escolas do município com o patrocínio da Prefeitura para que esse patrimônio imaterial se perpetue.

No Festival de Folclore de 2008 foram implementadas algumas adaptações, com organização de apresentações de batuques, cantigas de rodas e cantos, pelas crianças e jovens da Associação dos Pais e Amigos dos Excepcionais (APAE); do Programa de Erradicação do Trabalho Infantil (PETI) e do Centro de Referência da Assistência Social (CRAS).

A apresentação desses grupos foi um "aperitivo" que antecedeu às apresentações dos grupos "autênticos", possibilitando, dessa forma, vinculação entre o passado e presente das tradições culturais locais.

Essas ações podem motivar e atrair os mais jovens, os estudantes do município a participarem das performances na cidade e fora dela contribuindo para a divulgação da imagem de Jequitibá e colaborando para a continuidade dessa herança de danças e cantos tão presentes nessa localidade. Se a renovação não ocorrer, significa condenar determinados grupos a permanecer ancorados na tradição, "museus vivos" de passado idealizado, que sem a renovação correm riscos reais de perdas e de esquecimento na medida em que as vozes dos atores tradicionais dessas manifestações se calem. Essas mudanças realizadas pelos próprios atores mantêm a autenticidade das manifestações e seus sentidos sagrados e profanos, todavia transformadas para atender as aspirações do presente da comunidade e do mercado. Esses arranjos podem garantir a conservação dessas manifestações populares e propiciarem auto-estima para esses atores sociais.

A terceira estratégia é a de estabelecer um diálogo entre os performáticos e suas manifestações buscando de um lado resgatar o valor simbólico e histórico dessas tradições mantendo essa herança cultural e possibilitar uma releitura que seduza e 
amplie o público apreciador desse produto cultural. Essas intervenções podem propiciar um produto cultural de qualidade sem transformá-los em manifestações caricatas que não traduzam uma tradição que passou para o presente. Em 2008, ocorreram reuniões para a organização de uma associação dos grupos folclóricos de Jequitibá.

A quarta estratégia é a ação do poder público apoiando essas manifestações populares por serem da comunidade e que beneficiam a população local contribuindo para a auto-estima e a identidade local. O gestor público deve realizar investimentos na cultura do município e buscar recursos nas leis de incentivo federais e estaduais a cultura.

Com relação a essa última estratégia, o Festival de Folclore realizou-se em 2008 através da iniciativa do Poder Público local, que contratou o Instituto Jardim Cultural para desenvolver um projeto cultural, apresentado, no primeiro semestre de 2008, à Secretaria de Cultura de Minas Gerais. Por meio dessa iniciativa, obtiveram-se para aplicação no referido Festival recursos da ordem de $\mathrm{R} \$ 100.0000,00$ (cem mil reais), com base na Lei Estadual n. 17615/2008, que dispõe sobre a concessão de incentivo para estimular a realização de projetos culturais em Minas Gerais.

Essas ações intencionam preservar o patrimônio imaterial da comunidade, herança cultural dos grupos de trabalhadores rurais espalhados pelas diversas comunidades do município de Jequitibá, cujo patrimônio imaterial se manifesta nos cantos e danças e músicas de caráter sagrado e profano merecendo reconhecimento e respeito.

\section{CONCLUSÃO}

A organização do Festivelhas em 2007 e 2008 é uma conquista da cultura tradicional de Jequitibá produzida por atores sociais que com sua herança reafirmam a identidade da cidade ligada a essas tradições. O Festivelhas patrocinado pelo Manuelzão possibilita maior visibilidade às celebrações de Jequitibá que se realizam todo ano com um alcance local.

A relação entre o patrimônio e o turismo em Jequitibá é um importante fator de valorização e conservação do patrimônio imaterial, por trazer benefícios econômicos 
para a comunidade e promovendo o interesse da mesma na sua conservação. Essa aproximação entre o patrimônio e o turismo pode possibilitar a fruição dos excursionistas e turistas ao vivenciarem prazerosamente as celebrações expressas nos cantos, nas danças e música da cidade. O turismo ao promover o encontro entre os visitantes e os anfitriões contribui para o fortalecimento da identidade cultural do lugar e atua como elemento externo de transformação, com essa herança se adaptando à prática cotidiana, do presente e não apenas do passado. Cabe aos gestores e agentes do turismo criar uma relação equilibrada entre o valor econômico do patrimônio cultural e a identidade do lugar, processos que não são conflitantes e sim promotores de benefícios materiais e simbólicos.

O Festivelhas ocasiona a vinda de turistas interessados em vivenciar e discutir as questões ambientais e culturais da bacia do rio das Velhas não somente como perspectiva regional, mas também como uma questão ambiental global. A relação entre anfitriões e convidados foi tranqüila e prazerosa, sem nenhum registro de imprevistos ou acidentes. Eles trazem sua cultura pelas mãos e vozes dos artistas e participantes convidados e absorvem a cultura tradicional local alcançando um dos objetivos internacionais do turismo de promoção da paz e do intercâmbio cultural.

O Festivelhas representa um reforço na identidade local e da auto-estima expressados nas manifestações tradicionais ligadas ao catolicismo. O Festival está promovendo a cooperação entre os gestores públicos do município com os gestores do Projeto Manuelzão, entre esses gestores e a comunidade especialmente da iniciativa privada vinculada aos serviços de hospedagem, restaurantes e a associação dos artesãos existente no município. O evento representa também importante fonte de renda e ocupação direta e indireta para o município. Para DIAS (2006) o novo papel dos municípios diante da globalização passa pelo aproveitamento dos recursos endógenos como uma perspectiva para geração de renda, independente do governo central.

A festa promove o contato entre o tradicional e o moderno representado pelas atrações trazidas a cidade como os performáticos do internacional grupo Galpão Cine Horto, solistas que fundem o erudito com o popular, o grupo de músicos da Suíte para os orixás, fazendo com que a cultura local convivesse com contextos mais amplos. Em 2008 além da apresentação dos grupos locais aconteceram apresentações de Sarau do Tropeiro com Ricardo Evangelista e Sueli Silva; atrações internacionais como Tita 
Parra e Emílio Garcia do Chile; Chico Lobo, Pedro Mestre e a fadista Ana Valadas de Portugal. A geração de renda e ocupação de artesãos, de cozinheiras das barracas de alimentação e bebidas completa essa interconexão entre turismo e patrimônio que pode propiciar impactos positivos como o caso aqui analisado. Além da nova fonte de renda trazida pelos visitantes o intercâmbio entre anfitriões e convidados se mostra nesse evento propiciador de novas oportunidades para essa comunidade situada às margens do rio das Velhas onde a cultura sobreviveu pela persistência dos atores sociais. Atualmente apropriadas pelo turismo essas manifestações continuam mesmo que adaptadas atuando como legítimas fontes de sentido afetivo e de auto-estima e renda para a comunidade.

A valorização desse patrimônio imaterial de Jequitibá, representado nos cantos e danças ligados a ritos sagrados ou profanos desenvolvidos pelas comunidades que precisam ser registrados e valorizados com o patrocínio de empresas públicas e privadas e gestores públicos uma vez que esse patrimônio imaterial encontra-se debilitado não tendo como concorrer com a indústria cultural gerada nos grandes centros urbanos e que acabam por impor modelos, fórmulas e conceitos. A responsabilidade dos municípios e órgãos estatais como o Instituto Histórico e Artístico de Minas Gerais (Iepha/MG) na manutenção dessa tradição é fundamental, juntamente com a valorização desse patrimônio pela população local. Nesse sentido, festivais como o Festivelhas que ao promover o debate sobre as questões ambientais e culturais, ao trazer turistas culturais para a comunidade propiciam uma grande oportunidade de a cidade vivenciar o valor de sua herança cultural.

\section{REFERÊNCIAS}

ARANTES, A. A. Patrimônio imaterial e sustentabilidade de sua salvaguarda. DaCultura, ano 4, n. 7, Rio de Janeiro, 2004, p. 9-14.

BOLETIM FESTIVELHAS DE MÃO EM MÃO. Jequitibá/MG, 06-09 de setembro, 2007. (5 edições).

BRASIL. Constituição da República Federativa do Brasil: promulgada em 5 de outubro de 1988. São Paulo: Saraiva, 1990. (Série Legislação Brasileira). 
CARVALHO, J. J. Metamorfoses das tradições performáticas afro-brasileiras: de patrimônio cultural a indústria do entretenimento. In: Celebrações e saberes da cultura popular: pesquisa, inventário, crítica, perspectiva. Cecília Londres [et al.] Rio de Janeiro: Funarte, Iphan, CNFCP, 2004.

CURY, I. (Org.) Cartas patrimoniais. Rio de Janeiro: IPHAN, 2004.

BRASIL. Decreto n. 3551/2000, de 04 de agosto de 2000. Institui o registro de bens culturais de natureza imaterial que constituem patrimônio cultural brasileiro, cria o programa nacional do patrimônio imaterial e dá outras providências. In: $\mathbf{O}$ registro do patrimônio imaterial: dossiê final das atividades da comissão e do grupo de trabalho patrimônio imaterial. Brasília: Ministério da Cultura/Instituto do Patrimônio Histórico e Artístico Nacional, 2. ed., 2003.

DIAS, R. Sociologia do turismo. São Paulo: Atlas, 2003.

Turismo e patrimônio cultural: recursos que acompanham o crescimento das cidades. São Paulo: Saraiva, 2006.

ERNESTINA, Z. Entrevista concedida ao autor, Jequitibá/MG. 19 ago. 2007.

FELIZARDO, M. F. Entrevista. Boletim do Festivelhas de mão em mão, n. 5, 09 set. 2007.

FESTIVELHAS JEQUITIBÁ. Disponível em:

<http://manuelzao.ufmg.br/folder_atuacao/folder_festivelhas>. Acesso em: 04/09/2007.

FESTIVAL DE FOLCLORE DE JEQUITIBÁ/MG 2008. Disponível em: $<$ http://folclorejequitiba.com>. Acesso em: 10/02/2009.

ICOMOS, Carta do Turismo Cultural. In: SEMINÁRIO INTERNACIONAL DE TURISMO CONTEMPORÂNEO E HUMANISMO. Bruxelas, 1976.

LARAIA, R. de B. Cultura um conceito antropológico. Rio de Janeiro, Zahar, 2006.

LONDRES, C. Para além da pedra e cal: por uma concepção ampla do patrimônio. Revista Tempo Brasileiro, n. 147, out./dez., 2001.

MINAS GERAIS. Lei n. 17.615, de 04 de julho de 2008. Dispõe sobre a concessão de incentivo fiscal com o objetivo de estimular a realização de projetos culturais no Estado. Disponível em: <http://www.cultura.mg.gov.br>. Acesso em: 29/01/2009.

OEA/Normas de Quito. In: CURY, I. (Org.) Cartas patrimoniais. Rio de Janeiro: IPHAN, 2004.

SANTOS, N. Entrevista concedida ao autor, Jequitibá/MG. 21 set. 2007. 
VIEIRA FILHO, N. A. Q.; DUARTE, G.; SOUZA, T. R. Os impactos do turismo sobre a arte e o artesanato em Tiradentes, Minas Gerais. SEMINÁRIO DE PESQUISA EM TURISMO DO MERCOSUL, Universidade de Caxias do Sul, 2006.

Recebido em: 28/01/2009

Aprovado em: 28/02/2009 